\title{
Paracaval pseudolipoma mimicking intracaval mass lesion and thrombus
}

\author{
Mohammed Sachal, ${ }^{1}$ Amir Humza Sohail, ${ }^{2}$ Muhammad Salman Khan, ${ }^{2,3}$ \\ Wasim Memon ${ }^{2,3}$
}

\begin{abstract}
${ }^{1}$ Medical student, King Edward Medical University, Lahore, Pakistan

${ }^{2}$ Medical College, Aga Khan University, Karachi, Pakistan ${ }^{3}$ Department of Radiology, Aga Khan University, Karachi, Sindh, Pakistan
\end{abstract}

\section{Correspondence to} Amir Humza Sohail, ameer.hamzasohail@gmail.com

Accepted 30 June 2018

\section{DESCRIPTION}

A 53-year-old man presented with moderate dull non-radiating right upper quadrant pain for the past 1 month. There were no exacerbating or relieving factors or associated symptoms. His medical history was positive for hepatocellular carcinoma for which segmentectomy was performed 6 months ago. On physical examination, he was vitally stable and all systemic examinations were unremarkable. Contrast-enhanced abdominal CT scan showed an enhancing lesion at the surgical bed, representing recurrence of hepatocellular carcinoma (figure 1 and 2). There was also an apparently intracaval fat-density lesion in the suprahepatic part (figure 1 and 2). However, on detailed inspection, particularly on sagittal images (figure 3), its extracaval location became evident, and it was diagnosed as a paracaval pseudolipoma.

Pericaval and juxtacaval pseudolipoma mimicking an intracaval mass/thrombus occurs in $0.5 \%$ of adults undergoing abdominal CT scan. ${ }^{1}$ It is found posteriorly or medially to the IVC lumen and can appear different in serial CT scans due to different respiratory depth and pressure. ${ }^{1}$ The rightward angulation of the IVC and narrowing of the intrahepatic IVC causes the fat in this location to appear within the lumen, particularly on axial images. $^{2}$

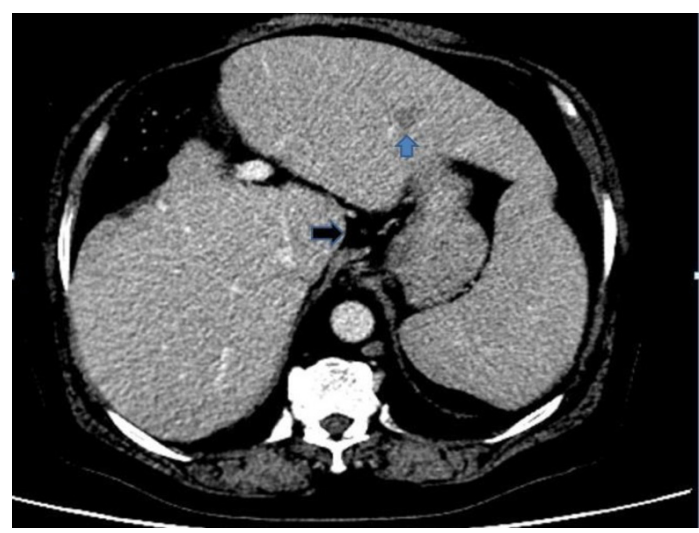

Figure 1 Contrast-enhanced CT scan axial section showing fat density compressing the inferior vena cava (IVC) representing paracaval pseudolipoma, mimicking IVC thrombus/tumour (black arrow). Enhancing lesion in the right lobe of the liver, which shows wash out on portovenous phase representing hepatocellular carcinoma (blue arrow).

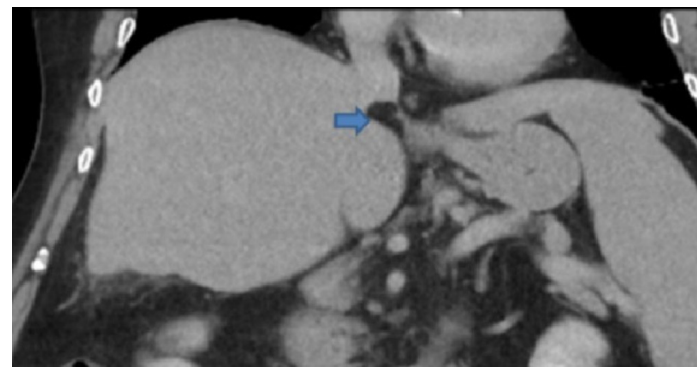

Figure 2 Contrast-enhanced CT scan coronal section showing fat density compressing the IVC representing paracaval pseudolipoma, mimicking IVC thrombus/ tumour (blue arrow).

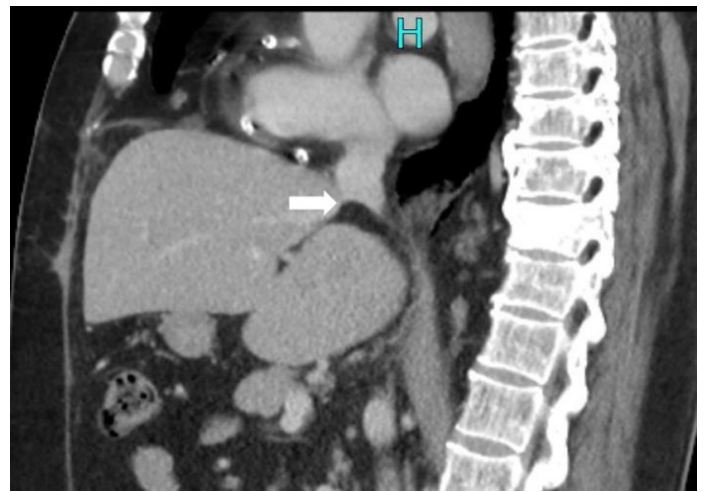

Figure 3 CT sagittal section venous phase showing the fatty lesion (white arrow) in the pericaval location.

Cognisance of this entity can prevent misdiagnosis and the resulting unnecessary therapy and interventions. CT attenuation values are important when dealing with such masses in the caval region. The uniformity of fat-density seen in these fat collections should enable differentiation from other possible diagnoses. Furthermore, ultrasound and multiplanar reformation of CT images can also prove instrumental in discerning this condition. ${ }^{23}$

Learning points

- Cognisance of pericaval and juxtacaval pseudolipoma mimicking an intracaval mass/ lesion can prevent misdiagnosis and the resulting unnecessary therapy and interventions.

- CT attenuation values and the uniformity of fat-density in these collections can be used to differentiate them from other possible diagnoses. 
Contributors All authors contributed to the case report. MS and AHS wrote the case. MSK and WM supervised the project.

Funding The authors have not declared a specific grant for this research from any funding agency in the public, commercial or not-for-profit sectors.

Competing interests None declared.

Patient consent Obtained.

Provenance and peer review Not commissioned; externally peer reviewed.

\section{REFERENCES}

1 Miyake H, Suzuki K, Ueda S, et al. Localized fat collection adjacent to the intrahepatic portion of the inferior vena cava: a normal variant on CT. AJR Am J Roentgenol 1992;158:423-5.

2 Han BK, Im JG, Jung JW, et al. Pericaval fat collection that mimics thrombosis of the inferior vena cava: demonstration with use of multi-directional reformation CT. Radiology 1997;203:105-8.

3 Sodhi KS, Saxena AK, Khandelwal N, et al. Pseudolipoma of the inferior vena cava. Indian I Surg 2014;76:413-4.

Copyright 2018 BMJ Publishing Group. All rights reserved. For permission to reuse any of this content visit http://group.bmj.com/group/rights-licensing/permissions.

BMJ Case Report Fellows may re-use this article for personal use and teaching without any further permission.

Become a Fellow of BMJ Case Reports today and you can:

- Submit as many cases as you like

- Enjoy fast sympathetic peer review and rapid publication of accepted articles

- Access all the published articles

Re-use any of the published material for personal use and teaching without further permission

For information on Institutional Fellowships contact consortiasales@bmjgroup.com

Visit casereports.bmj.com for more articles like this and to become a Fellow 